DIW BERLIN

Discussion

Papers
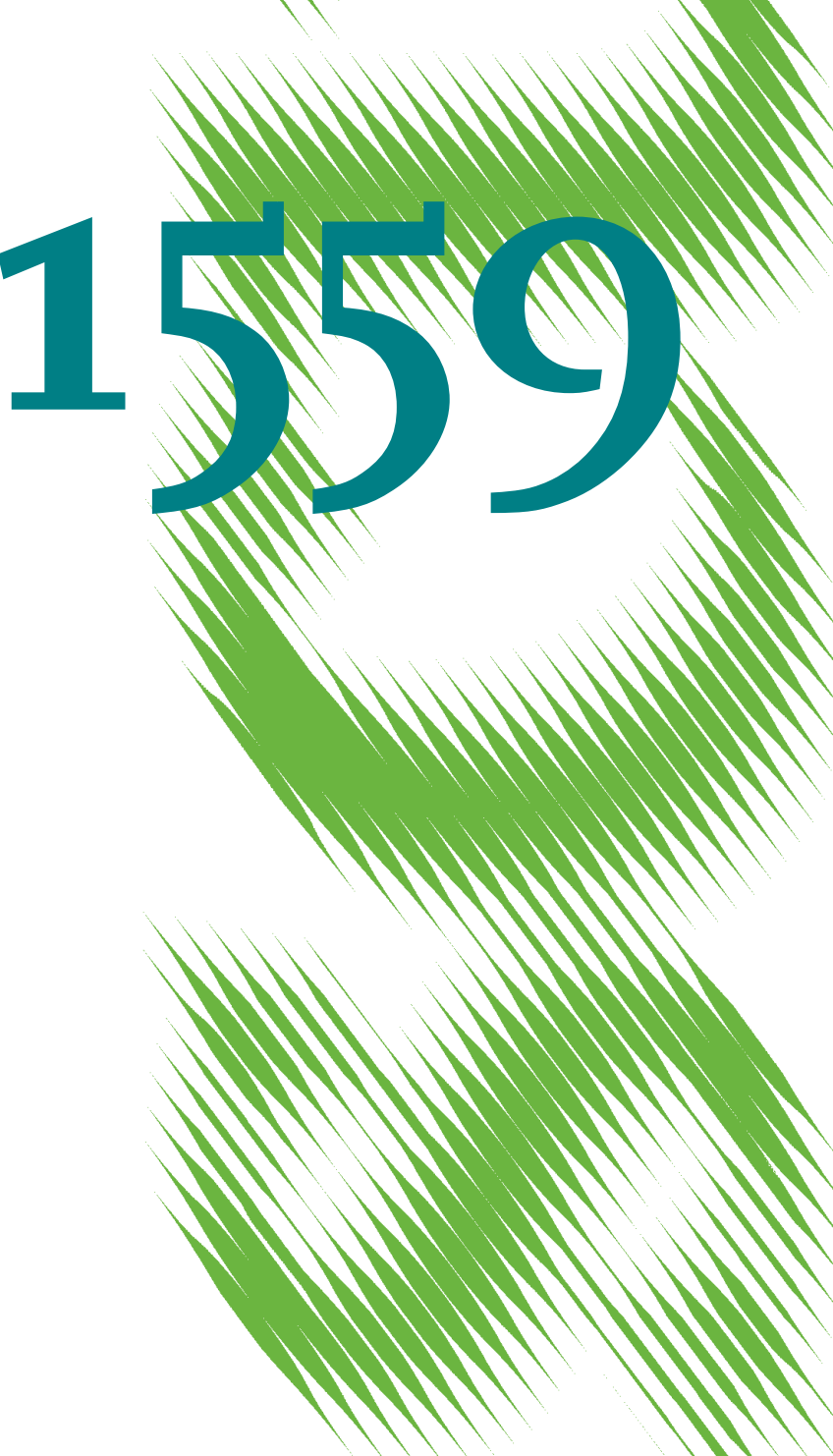

MMI

MMMMMMMIMI

\title{
Monetary Policy and Defaults
} in the US 
Opinions expressed in this paper are those of the author(s) and do not necessarily reflect views of the institute.

IMPRESSUM

(C) DIW Berlin, 2016

DIW Berlin

German Institute for Economic Research

Mohrenstr. 58

10117 Berlin

Tel. +49 (30) $89789-0$

Fax +49 (30) $89789-200$

http://www.diw.de

ISSN electronic edition 1619-4535

Papers can be downloaded free of charge from the DIW Berlin website:

http://www.diw.de/discussionpapers

Discussion Papers of DIW Berlin are indexed in RePEc and SSRN:

http://ideas.repec.org/s/diw/diwwpp.html

http://www.ssrn.com/link/DIW-Berlin-German-Inst-Econ-Res.html 


\title{
Monetary Policy and Defaults in the US
}

\author{
Michele Piffer* \\ DIW Berlin
}

December 22, 2015

\footnotetext{
*DIW Berlin, Moherenstrasse 58, 10117, Berlin, Germany. Email: m.b.piffer@gmail.com. $\quad$ Telephone: $\quad+49 \quad(0) 30 \quad 89789$ 454. Personal web page: https://sites.google.com/site/michelepiffereconomics/. I thank Wouter Den Haan for his priceless guidance. I also thank Saleem Bahaj, Luca Fornaro, Leonardo Gambacorta, Jochen Günter, Ethan Ilzetzki, Michael McMahon, Jean-Stephane Mesonnier, Pascal Paul, José Peydró, Max Podstawski, Malte Rieth, Paolo Surico and Thijs van Rens for comments and suggestions. The paper benefited from financial support from the Fondazione Eni Enrico Mattei, from the Economic and Social Research Council, and from Banca Popolare Commercio e Industria.
} 


\begin{abstract}
This paper uses a structural VAR model to study the effect of monetary policy on the delinquency rate of business loans and consumer credit. The VAR is identified using at the same time several external instruments, which cover different approaches from the literature. Delinquency rates, defined as the rate of loans whose repayment is overdue for more than a month relative to total loans, are found to decrease in response to a monetary expansion. The results are consistent with a general equilibrium effect formalized in the paper using a standard model of optimal defaults. According to the model, the decrease in defaults is driven by the fact that monetary expansions increase aggregate demand and push up profits and income, thereby improving the repayment possibility of borrowers.
\end{abstract}

Keywords: Monetary shocks, risk-taking channel, SVAR with external instruments

JEL Classification: E52, E58 


\section{Introduction}

This paper studies the effect of monetary policy on the delinquency rate of business loans and consumer credit in the US. Since delinquent loans are loans whose repayment is overdue for more than 30 days, the ratio of delinquent to total loans (the delinquency rate) is closely monitored by the Federal Reserve Bank as a measure of the quality of loans, and as a proxy for the default probability of loans.1 The paper first studies the effect of monetary policy on delinquencies empirically using a structural VAR model identified with external instruments, following the methodology of Mertens and Ravn (2013) and Stock and Watson (2012). It then uses comparative statics on the debt contract of Townsend (1979) and Bernanke et al. (1999) to develop an economic intuition of what might drive the empirical results.

From an empirical point of view, identifying the causal effect of a monetary intervention on the default rate of loans is not straightforward, as one needs to establish if the federal funds rate is exogenous to delinquency rates. It could be argued that the federal funds rate is exogenous to expected future defaults. For instance, financial stability concerns rarely appear in the Minutes of the FOMC before the 2007 crisis, as documented by Dell'Ariccia et al. (2013). However, while not set directly as a function of future defaults, the federal funds rate might respond to expected future defaults indirectly, given that defaults are correlated with economic activity $\left.\right|^{2}$ As such, an impulse response that predicts that a monetary

\footnotetext{
${ }^{1}$ See for instance the following speech by former Chairman Ben Bernanke in May 2008, http://www.federalreserve.gov/newsevents/speech/bernanke20080505a.htm.

${ }^{2}$ In a December 3, 2014 speech, Governor Lael Brainard discusses the fact that financial stability concerns always played a relevant part in the conduct of monetary policy by the Federal Reserve Bank. See http://www.federalreserve.gov/newsevents/speech/brainard20141203a.htm.
} 
expansion increases delinquency rates might still be driven by the fact that the Federal Reserve Bank expanded monetary policy in anticipation of a downturn in economic activity.

In the empirical part of the paper, I address the above identification challenge using a VAR model for the period between 1987Q1 and 2008Q4, and identify the model using external instruments. I use several instruments for monetary policy shocks, combining in a 2SLS estimation the instruments generated by the three most widely used approaches in the literature. In particular, I use the Romer and Romer shocks (developed by Romer and Romer, 2004), the shocks identified from a recursive large VAR model (for which I use the estimates by Bańbura et al., 2010) and the shocks estimated from futures contracts on the federal funds rate (which I take from Barakchian and Crowe, 2013). The advantage of this comprehensive approach is that it avoids having to choose a single identification strategy, a choice which would prove hard given the limited consensus in the literature on which methodology is the best one. The Proxy VAR based on the instruments used in this paper combines the information content of the Federal Reserve Banks' expectations included in the Greenbook forecasts, the information content of a large dataset used in the VAR and the model-free information content from high-frequency data from financial markets. For robustness, I also propose an orthogonalization of the shocks with regard to a set of financial variables.

The empirical part of the paper finds that an expansionary monetary policy shock decreases the delinquency rate of both business loans and consumer credit. This decrease occurs around 8 quarters after the initial impact and is statistically meaningful. The result raises the question what economic incentives might drive 
defaults to decrease. From a theoretical point of view, whether a monetary expansion should increase or decrease defaults is a priori ambiguous. On the one hand, a monetary expansion is likely to generate general equilibrium effects on borrowers' income and profits in line with the "credit view", as a result of the rightward shift of aggregate demand. This would decrease defaults since the wealth of borrowers expands. On the other hand, as discussed below, monetary expansions have been documented to generate risk-taking effects by leading banks to issue loans to more risky borrowers. To the extent that this partial equilibrium effect dominates in equilibrium, ex post defaults might increase, rather than decrease, following a monetary expansion. I use an off-the-shelf model featuring a debt contract and optimal defaults to discuss the interaction of these partial and general equilibrium effects.

The literature on monetary policy and central banking has dedicated considerable attention to the incentives of banks to take on more risk after monetary expansions. This has been done using either microeconomic data (for example by Jimenez et al., 2014, Maddaloni and Peydro, 2013 and Altunbas et al., 2014) or aggregate variations in credit standards (Buch et al., 2014a and Afanasyeva and Güntner, 2014) and leverage (Angeloni et al., 2015). The present paper does not directly inspect the risk taking channel of monetary policy, which relates to an ex ante incentive by banks to issue new loans and would require a different type of data. However, an indirect link to the risk taking literature can be established from the fact that the average maturity of loans in the dataset is only 5 quarters. This means that, on average, the documented decrease in delinquency rates following a monetary expansion regards at least in part newly issued loans. 
While most of the attention in this literature has regarded the ex ante incentives to take on risk, Buch et al. (2014b) extend the analysis to study if ex post, backwardlooking measures of risk are capable of signalling the additional risk. Using a sign restricted VAR model, they find that the share of nonperforming loans held by banks decreases after a monetary expansion, and interpret the result in terms of the positive effect of monetary policy on the interest rate burden on firms. I contribute to the literature by providing further empirical evidence that backward looking measures of risk tend to decrease after a monetary expansion, and I do so using a Proxy VAR model. I then show that the general equilibrium effect used to interpret the results in this paper as well as in Buch et al. (2014b) is consistent with an off-the-shelf model featuring a credit channel. The empirical results are

also consistent with Jimenez et al. (2014), who find that the default probability of existing loans decreases after a monetary expansion, and De Graeve et al. (2008), who find that banks' probability of distress decreases after a monetary expansion.

The paper is organized as follows. Section 2 develops the empirical analysis, discussing the data, the identification strategy and the results. Section 3 outlines the key mechanism behind a standard model of defaults and uses comparative statics to interpret the results. Section 4 concludes.

\section{A Proxy SVAR on delinquency rates}

This section discusses the data used to measure defaults and introduces the different series of monetary shocks used to identify the structural VAR model. It then discusses the results of the model. 


\subsection{Data on delinquency rates}

A borrower is officially considered delinquent on a loan if the loan repayment (interests or principal) is overdue for more than 30 days. The delinquency rate is defined as the ratio of the value of delinquent loans over the value of outstanding loans. The Federal Reserve Bank collects data on delinquency rates from the Call Report, which is filed quarterly on a compulsory basis by all US-chartered commercial banks. For confidentiality reasons, only a limited set of aggregate time series is made publically available.

I use two aggregate delinquency rates, which are the delinquency rates on business loans and on consumer credit, respectively. The data used covers the time between 1987Q1 (first period available) to 2008Q4 (starting from which the US monetary policy was constrained by the zero lower bound). The delinquency rates used refer to loans issued by all commercial banks. According to Flow of Funds data, the correlation of the value of these loans with the monetary aggregate M2 equals $86 \%$ and $92 \%$, respectively. Overall, business loans and consumer credit jointly account for around $25 \%$ of banks' total assets $3^{3}$

Figure 1 shows the evolution of the deseasonalized delinquency rates used in the analysis. The average of the delinquency rates on business loans and consumer credit equals $3.10 \%$ and $3.43 \%$, respectively, while the standard deviations equal 164 basis points and 37 basis points, respectively. Both series are strongly countercyclical. In particular, the period covered includes several cycles, i.e. the build

\footnotetext{
${ }^{3}$ The Federal Reserve Bank also provides data on the delinquency rate of residential mortgages. I do not use this data because it is available only starting from 1991, and because it displays very limited variation before the 2007 crisis, if compared to the delinquency rates on business loans and on consumer credit.
} 
up of delinquencies during the recession in the early 1990s, the recession that followed the dotcom bubble and the period of high financial instability that began in summer 2007.

\subsection{Monetary shocks}

Identifying the effects of monetary policy on delinquency rates requires isolating fluctuations in the federal funds rate that are exogenous to the Federal Reserve's expectations of future delinquency rates (see also Cochrane, 2004, for a comment on this point). The literature has developed several methodologies to estimate monetary shocks. Since it is not clear a priori which of these methodologies is more likely to deliver shocks that are exogenous to the Federal Reserve's forecasts of defaults, I identify the SVAR developed in the next section using simultaneously different candidate shocks. In particular, I use the time series of candidate monetary shocks representing the three most popular approaches from in the literature.

The first series of monetary shocks is taken from Romer and Romer (2004). These shocks are obtained from the residual in the regression of an index of the intended variations of the federal funds rate on the Federal Reserve's forecasts of real output growth, the GDP deflator, and the unemployment rate. The second series is taken from a recursively identified large VAR model by Bańbura et al. (2010). I use the medium specification of their model, which includes twenty variables ${ }^{4}$ The third series of monetary shocks is taken from Barakchian and

\begin{tabular}{l}
${ }^{4}$ The variables included in the replicated Medium Bayesian VAR are personal income, con- \\
\hline sumption, industrial production index, capital utilization, unemployment rate, number of em- \\
ployees on non farm sector, housing starts, producer price index, the price index of personal \\
\hline consumption expenditures, the CPI index, the trade-weighted US dollar index, hourly earnings \\
of production, the federal funds rate, M1, M2, total reserves, non borrowed reserves, the industrial \\
\hline production index, business loans, and loans on residential real estate. \\
\hline
\end{tabular}


Crowe (2013). They build on Kuttner (2001) and compute the variation in the policy rate that was not expected by the markets, using different maturities on the futures contracts on the federal fund rate. Only the period after 1987Q1 of the original series of the shocks is used in the analysis. The Romer and Romer shocks are estimated using the data collected by Coibion et al. (2012), who extend the analysis by Romer and Romer (2004) up to 2008M12.5 The discussion of the computation of all these shocks is available in the original papers.

The simultaneous use of several monetary shocks to identify impulse responses exploits the information content delivered by several approaches, hence improving upon the identification of the model. It is reasonable to expect that the Romer and Romer shocks are at least in part exogenous to the Federal Reserve's forecast of defaults, since future GDP is realistically correlated with the future financial position of borrowers. At the same time, a large VAR model is likely to include a rich set of information available to the Federal Reserve when taking decisions of monetary policy. Last, monetary shocks computed from data on futures contracts are less model-dependent. The identification of the VAR model through external instruments accounts for noise in the estimation of the monetary shocks.

All shocks are windsorized at $1 \%$ in order to avoid results from being driven by few outliers, and are standardized by dividing each series by the corresponding standard deviation. The period covered by the shocks goes from 1989Q1 to 2008Q2. However, the VAR will be estimated in the period from 1987Q1 to 2008Q4. The length of the period covered is consistent with Buch et al. (2014b) and several other contributions.

\footnotetext{
${ }^{5} \mathrm{I}$ am grateful to the authors for having shared their statistics.
} 
Figure 2 shows the monetary shocks as they enter the identification discussed in the following section. The three shocks take all together either positive value or negative value around $55 \%$ of the time. The correlations between the Romer and Romer shocks and the other two series of shocks is positive (22\% and $16 \%$, respectively) and highly statistically significant. The correlation between the shocks from the large VAR and the shocks from Futures contracts is instead negative, although not in a statistically significant way. Overall, the different candidate monetary shocks give a relatively coherent picture, although with important differences. There are two periods in which the three shocks are particularly similar. The first one around year 1995, when all shocks indicate monetary contractions, the second one in year 2007, around which all shocks moved from being contractionary to being expansionary.

The shocks discussed in this section are used as instruments to identify the VAR model of the next section.

\subsection{Identification of the VAR and impulse responses}

I use a parsimonious VAR model consisting of five variables: log of CPI, log of GDP, the federal funds rate, the delinquency rate of business loans and the delinquency rate of credit loans ${ }^{6}$ The VAR model can be written as

$$
y_{t}=\delta+A(L) y_{t-1}+u_{t}, u_{t}=B \epsilon_{t} \quad, \quad \epsilon_{t} \sim N(0, I)
$$

\footnotetext{
${ }^{6}$ A larger model would imply a significant loss of degrees of freedom, given that delinquency rates are available only from 1987Q1.
} 
where $\delta$ includes a constant and a linear trend, and the autoregressive component in matrix $A(L)$ includes 1 lag, as suggested by both the Bayesian and the Akaike Information Criteria.

The identification of the model consists of estimating the $5 \times 1$ vector $b$ of the $B$ matrix in equation (1). This can be seen after rewriting the reduced form innovations of the VAR as

$$
u_{t}=b \epsilon_{t}^{m p}+B^{*} \epsilon_{t}^{*}
$$

where $\epsilon_{t}^{m p}$ is the monetary shock of interest, $b$ is the impulse vector corresponding to the monetary shock, $B^{*}$ includes the columns of the $B$ matrix not corresponding to the monetary shock and $\epsilon_{t}^{*}$ includes the non-monetary shocks.

As discussed in Mertens and Ravn (2013), Stock and Watson (2012) and Gertler and Karadi (2015), to identify $b$ call $j=3$ the equation in which the federal funds rate enters as dependent variable. As a first step, project $u_{j t}$ on $m_{t}$, where $u_{j t}$ is the reduced form VAR innovation of equation $j$ at time $t$ and $m_{t}$ represents the vector of all instruments at time $t$. Then regress each of the remaining VAR residuals $u_{i, t}$ on the fitted value of the above regression, and store the coefficient $\gamma_{i}$. Last, combine the computed vector $\left(\gamma_{1}, \gamma_{2}, 1, \gamma_{4}, \gamma_{5}\right)^{\prime}$ with the covariance restrictions $\hat{\Sigma}=B B^{\prime}$ from the VAR to estimate the vector $\hat{b}$.

The above statistic $\hat{b}$ is a consistent estimator for $b$ provided that the validity of the instruments is satisfied. With regard to the application of external instruments to VAR models, the validity condition consists two requirements. First, that the instruments are correlated with the shock of interest (i.e. $E\left(s_{t}^{m p} m_{t}\right) \neq 0$ ). Second, that the instruments are not correlated with the remaining shocks (i.e. $E\left(s_{t}^{*} m_{t}\right)=$ 0 ). These conditions are fundamentally untestable. However, the strength of the 
instruments can be assessed by studying the relationship between the instruments and the VAR innovations. This can be done for example by regressing each VAR innovations on the instruments. The results of these tests are shown in Table 1. The $F$ statistic of the joint significance of the coefficients corresponding to the three shocks in the equation of the policy variable is above 10 and suggests that the instruments are jointly valid with regard to the application of the VAR considered. The $R^{2}$ in this regression equals 0.30 .

Mertens and Ravn (2013) compute confidence intervals using a Wild bootstrap.7 As shown in Figure 6, in the application of this paper such procedure yields extremely wide confidence intervals, probably due to the limited availability on data on delinquency rates. For this reason, I compute confidence bands using a standard bootstrap that accounts for estimation uncertainty of the reduced for VAR and partly for identification uncertainty. 8

Structural analysis is carried out on the responses of the variable in the VAR to an expansionary monetary shock of one standard deviation. The results are reported in Figure 3. The one standard deviation shock decreases the federal funds rate by approximately 25 basis points. This increases both CPI and real GDP within the first quarter after the shock. Real GDP displays a hump-shaped

\footnotetext{
${ }^{7}$ This bootstrap procedure consists of two steps. First, generate pseudo VAR innovations by randomly changing sign of the vector estimated VAR innovations at each period and by generating pseudo data from the pseudo residuals. Second, identify the model estimated on pseudo data using pseudo instruments, which differ from the original instruments for the sign, which has been changed for all periods in which the sign of the reduced form innovations was changed.

${ }^{8}$ The bootstrap procedure first generates pseudo data by bootstrapping on the entire vector of estimated VAR innovations, which is in turn achieved by randomly selecting, for each period $t$, a vector of estimated innovations out of the entire set of vectors from $t=1,2, \ldots, T$. This yields an empirical distribution of $\hat{A}(L)$ and $\hat{\Sigma}$ from equation (1), with $\Sigma=B B^{\prime}$. The algorithm then identifies the model estimated on pseudo data using the generated $\hat{\Sigma}$ and the original (rather than the bootstrapped) instruments. Figure 6 also considers alternative bootstrapping procedures.
} 
response. After the initial expansion, monetary policy endogenously becomes contractionary, following a timing that is consistent with the increase in CPI and real GDP. Delinquency rates respond slowly and decrease in a statistically significant way. The initial 25 basis point reduction in the federal funds rate decreases the delinquency rate of business loans and on consumer credit by around 13 and 6 basis points, respectively. This equals around $8 \%$ and $15 \%$ of the corresponding standard deviations, respectively, suggesting that the results are economically meaningful, although not large. The minimum is reached around 2 years after the monetary stimulus.

\subsection{Robustness checks}

It has been discussed in Section 2.2 that for the purpose of the analysis in this paper, monetary shocks should not reflect the Federal Reserve Bank's direct or indirect expectation of future defaults. To study if the results from Figure 3 are robust to the specification of the candidate monetary shock used, I conduct two exercises. In the first exercise, I still identify the model using jointly the three series of monetary shocks as instruments, but I first orthogonalize them with respect to a selection of financial variables. This is done to reduce the risk that the candidate monetary shocks contain information, available to the Federal Reserve Bank, informative of the future course of the delinquency rates. In the second exercise, I identify the model using as instruments the original candidate monetary shocks one at the time, instead of together.

The thought experiment behind the first exercise can be rationalized as follows. While unobserved, the Federal Reserve's expectation at time $t$ of future defaults is 
realistically some unknown function of variables, up to time $t-1$, that are informative of the future financial strength of borrowers. Financial variables that could proxy the unobserved expected defaults are the previous values of the delinquency rates, the previous values of the leverage ratios, the previous values of the debt-toGDP ratio of firms and of households, and the previous values of banks' reserves to total loans. To reduce the risk that the three series of candidate monetary shocks include information potentially informative of future delinquency rates, I extract the first $r=1,2, . ., 7$ principal components of the above 7 variables and regress the candidate series of monetary shocks on the first lag of the principal component(s). The generated "orthogonalized" shocks are then used to identify the model, as outlined in the previous section.

The results of this exercise are reported in Figure 4 . The figure is constructed by overlapping Figure 3 with the point estimates of the impulse responses computed on the orthogonalized monetary shocks when using $r=1,2, . ., 7$ principal components. These explain a minimum of $40 \%$ of the variability in the variables included 9 All generated impulse responses are very close to the point estimate from the baseline specification. The $F$ statistics on the residual of the federal funds rate from Table 1 (unreported) remained in the range between 9.5 and 11.5, supporting the strength of the instruments used. The confidence intervals (unreported) became in certain cases wider, but by very little.

I then considered the role of each of the three candidate series of monetary shocks in driving the results discussed in Figure 3. This was done by identifying the model using each original series of monetary shocks in isolation instead of all

\footnotetext{
${ }^{9}$ The order of the share of variability explained by the principal components is $0.40,0.75,0.88$, $0.95,0.96,0.98,1$.
} 
together. The results are shown in Figure 5, comparing the baseline specification for simplicity only to the point estimates of the impulse responses computed in the new scenarios (for the full analysis, see Figures 7 to 9). The impulse responses computed using only the Romer and Romer shocks and the shocks from the large VAR are shown with the squared and the circled lines, respectively. The $F$ statistics corresponding to the federal funds rate in Table 1 for these two cases equal 19 and 9, respectively, suggesting that the Romer and Romer shocks are particularly strong instruments. From Figure 5, we see that the results on the effect on the delinquency rates remains largely unchanged. The response of CPI using the shocks from the large VAR is surprisingly strong on impact, suggesting that it is these shocks that drive the relatively fast contemporaneous response of CPI from Figure 3. The response estimated using the shocks from Futures contracts are reported with the dashed line. On first impression, the responses seem to contradict the result that delinquency rates decrease in response to a monetary expansion. However, closer inspection suggests that this response cannot safely be interpreted as a monetary expansion since output decreases on impact and in a statistically significant way. The $F$ statistic is also small and equals 5 .

\section{A simple model of defaults}

The empirical analysis in the previous section does not find empirical evidence that delinquency rates increase in response to an exogenous monetary expansion. The results point towards a decrease in the delinquency rate of both business loans and consumer credit, where the response occurs relatively slowly and with the strongest 
effect around two years from the shock. This section uses a simplified and standard debt contract to interpret this empirical results.

The model, which consists of the debt contract by Townsend (1979) used in Bernanke et al. (1999), is not used to replicate quantitatively the responses from Figure 3, but to develop intuition of the incentives that might drive the documented response of delinquency rates. The intuition suggested by the model is that, other things equal, a monetary expansion would increase probabilities of default because borrowers leverage up their net worth. However, in general equilibrium this effect does not materialize, because the monetary expansion stimulates aggregate demand and increases firms profits and income. To the extent that the general equilibrium effect dominates, defaults decrease. It is this general equilibrium effect that potentially drives the decrease in delinquency rates documents in the previous section, as well as the decrease in nonperforming loans documented by Buch et al. $(2014 b)$.

\subsection{Environment}

A risk-neutral borrower has limited net worth $N$. At the beginning of the period he borrows $K-N$ from a risk-neutral lender, where $K$ stands for the level of investment. The borrower has access to the following production function:

$$
y=\omega R_{K} K
$$

The shock $\omega$ represents an idiosyncratic productivity shock with support $[0, \infty)$, expected value of 1 and cumulative distribution function $\Psi(\omega) . R_{k}$ stands for the 
aggregate return on the risky technology.

In a general equilibrium environment $R_{k}$ is stochastic and is unexpectedly pushed up by the monetary expansion due to an outward shift of the aggregate demand curve. This is, for instance, the case in the Bernanke, Gertler and Gilchrist (1999) application of the model. I simplify the analysis by treating $R_{k}$ as deterministic and by using comparative statics. The contract is signed at the beginning of the period. The shock $\omega$ is realized at the end of the period. $\omega$ is costlessly observed by the borrower, but it is not observed by the lender unless she pays a fraction $\mu<1$ of ex post revenues $\omega R_{k} K$. The borrower obtains credit from a lender in competitive markets. The contract maximizes the expected profits of the borrower under the condition that the expected return on lending equals the gross opportunity cost of lending $R{ }^{10}$

\subsection{Debt contract}

Townsend (1979) shows that, in this setting, the optimal contract is a simple debt contract, i.e., the borrower either repays a fixed amount independently on the realization of the shock or defaults ${ }^{11}$ Let $R_{b}$ stand for the gross borrowing rate. When the borrower and the lender agree on $K-N$ and $R_{b}$ they indirectly agree on an endogenous threshold value $\bar{\omega}$ below which the borrower's revenues are

\footnotetext{
${ }^{10}$ Note that, in this model, the risk-taking incentive of the lender takes the form of accepting that the borrower leverages up his net worth and runs a higher default probability, because the lender is appropriately compensated for it. This mechanism is not the only plausible one. An additional, complementary mechanism is that lenders find it profitable to shift towards borrowers who finance more risky projects. Modelling the interaction of both forces goes beyond the purpose of the paper, which is to discuss the plausibility of a general equilibrium effect.

${ }^{11}$ The intuition behind the optimality of the debt contract is that it is optimal to limit the probability that the dead-weight observation cost is incurred. To do so, the lender leaves no revenue to the borrower in case of default in order to reduce the borrowing rate to be paid in case of no default.
} 
insufficient to cover the debt repayment obligation. This threshold value is pinned down by $\bar{\omega} R_{k} K=R_{b}(K-N)$. If $\omega>\bar{\omega}$, then the borrower pays back $R_{b}(K-N)$ and keeps profits $\omega R_{k} K-R_{b}(K-N)$. If $\omega<\bar{\omega}$, then the borrower defaults and the lender recovers $(1-\mu) \omega R_{k} K$.

The maximization problem is solved in $\bar{\omega}, R_{b}, K$ and is written as

$$
\begin{gathered}
\max _{\left\{\bar{\omega}, R_{b}, K\right\}} \int_{\bar{\omega}}^{\infty} \omega R_{k} K-R_{b}(K-N) d \Psi(\omega), \quad \text { subject to } \\
\bar{\omega} R_{k} K=R_{b}(K-N), \\
{[1-\Psi(\bar{\omega})] R_{b}+\Psi(\bar{\omega})(1-\mu) \frac{E(\omega \mid \omega<\bar{\omega}) R_{k} K}{K-N} \geq R .}
\end{gathered}
$$

Equation (2) defines the threshold value $\bar{\omega}$ as a function of $R_{b}$ and $K$. Equation (3) gives the participation constraint of the lender. This constraint imposes that the expected return on lending is not lower than the opportunity cost of lending. Ex post variations of $R_{k}$ move $\bar{\omega}$ in the opposite direction, given that the remaining variables in equation (2) are determined at the beginning of the period.

Substitute $R_{b}$ from equation (2) into equation (3) and into the objective function in order to simplify the maximization problem to

$$
\max _{\bar{\omega}, K} F(\bar{\omega}) R_{k} K, \quad \text { subject to } \quad \frac{K}{N} \leq \frac{1}{Q-\frac{R_{k}}{R} G(\bar{\omega})}
$$

with $F(\bar{\omega})=\int_{\bar{\omega}}^{\infty} \omega d \Psi(\omega)-[1-\Psi(\bar{\omega})] \bar{\omega}, G(\bar{\omega})=1-F(\bar{\omega})-\mu \int_{0}^{\bar{\omega}} \omega d \Psi(\omega)$. Tо develop intuition behind the notation, use $F(\bar{\omega})$ and $G(\bar{\omega})$ and the assumption $E(\omega)=1$ to derive the following equality: 


$$
\left[1-\mu \int_{0}^{\bar{\omega}} \omega d \Psi(\omega)\right] R_{k} K=R_{k} K[F(\bar{\omega})+G(\bar{\omega})]
$$

Equation (44) shows that $F(\bar{\omega})$ and $G(\bar{\omega})$ determine the shares of expected output $R_{k} K$ net of expected monitoring costs $\mu \int_{0}^{\bar{\omega}} \omega R_{k} K d \Psi(\omega)$ allocated to the borrower and the lender, respectively ${ }^{12}$ These shares are implicitly pinned down by the debt contract. It can be shown that, in the relevant support of $\omega, F^{\prime}(\bar{\omega})<0$ and $G^{\prime}(\bar{\omega})>0$. Borrowing conditions that indirectly imply a higher share of expected revenues to the borrower imply a lower share of expected revenues to the lender. An increase in the share of expected revenues promised to the lender $G(\bar{\omega})$ is associated with an increase in the default threshold $\bar{\omega}$, because it is harder for the borrower to meet the higher repayment obligation to the lender. Nevertheless, it has the benefit of relaxing the participation constraint of the lender. The equilibrium of the model is pinned down by this trade-off. To solve the maximization problem, substitute out $K$ from the objective function and derive the optimality condition with respect to $\bar{\omega}$ :

$$
-F^{\prime}\left(\bar{\omega}^{*}\right)=F\left(\bar{\omega}^{*}\right) \frac{G^{\prime}\left(\bar{\omega}^{*}\right)}{\left(\frac{R_{k}}{R}\right)^{-1}-G\left(\bar{\omega}^{*}\right)} .
$$

\subsection{Discussion of the equilibrium}

The threshold value $\bar{\omega}^{*}$ pinned down by equation (5) is a decreasing function of $R$ for any parametrization of the model (see Covas and Den Haan (2012), appendix

\footnotetext{
${ }^{12}$ The latter is best seen by rewriting the participation constraint as $G(\bar{\omega}) R_{k} K \geq R(K-N)$.
} 
C) ${ }^{13}$ This means that, given $R_{k}$, a decrease in the opportunity cost of lending, which proxies the policy rate changed by the central bank, increases the equilibrium default probability of the borrower. Nevertheless, in general equilibrium, this effect could be dominated by other effects. To develop the economic intuition that explains this difference I use a simple graphical representation.

Figure 10 shows, in the graphs on the left, combinations of leverage $K / N$ and $G(\bar{\omega})$ that satisfy the participation constraint of the lender. An increase in lending increases the borrower's leverage ratio, which reduces the relative buffer that the constant net worth provides to the risky loan. To compensate the lender for this leverage effect, the borrower must pay a leverage premium that takes the form of a higher $G(\bar{\omega})$, i.e. a higher share of expected revenues to the lender. All combinations of $\{(K, G(\bar{\omega})\}$ below the solid line in the left graph satisfy the participation constraint of the lender. The dash-dotted lines represent iso-profit curves of the borrower. The right graph shows the corresponding default probability. Given $R_{b}$ and $R_{k}$, a higher leverage ratio implies a higher default rate. ${ }^{14}$

The initial equilibrium is shown in panel a), point $A$. A decrease in the opportunity cost of lending $R$, panel b), rotates the constraint upwards and expands the set of combinations compatible with the participation constraint of the lender. This occurs because perfect competition pushes down the return on lending, implying now a lower borrowing rate for any given level of lending. If $K$ remains constant, the borrower borrows the same amount and pays a lower borrowing rate due to perfect competition. This would decrease the default probability. Never-

\footnotetext{
${ }^{13}$ Covas and Den Haan (2012) study the relationship between $\bar{\omega}^{*}$ and $R_{k}$. Their proof extends to the relationship between $\bar{\omega}^{*}$ and $R$.

${ }^{14}$ To see this, substitute equation (2) in the cumulative distribution function of $\omega$, obtaining $\operatorname{Prob}(\omega<\bar{\omega})=\Psi\left(\frac{R_{b}}{R_{k}}\left(1-\frac{1}{K / N}\right)\right)$.
} 
theless, borrowing the same amount is not optimal, since the discounted return to capital $R_{k} / R$ has increased, making each unit of investment more productive in discounted terms. Investing more requires moving along the new participation constraint of the lender and paying the lender a higher expected share of revenues $G(\bar{\omega})$, due to the leverage effect discussed above. In the partial equilibrium model, this leverage effect always dominates, taking the new equilibrium to point $B$. The new partial equilibrium features a higher default probability. Put it simply, debt becomes cheaper, the borrower demands more credit, and since his leverage ratio increases, his default probability increases.

Consider now the general equilibrium effect. In Bernanke, Gertler and Gilchrist (1999), the borrower is an entrepreneur who rents capital to intermediate good producers. The return to capital $R_{k}$ equals the rental rate on capital plus the capital gain on undepreciated capital. In their general equilibrium framework, the unexpected monetary expansion increases investments. This pushes up the price of capital, which in turn generates a positive capital gain and increases the return to capital, increasing the borrower's revenues and his future net worth. In the model, it is this increase in aggregate demand, through the increase in investments, that pushes up the borrower's income. This mechanism can be captured in a stylized way by assuming that the decrease in the opportunity cost of lending pushes up the value of $R_{k}$ at the end of the period, i.e. the value that enters equation (2). The effect on defaults can be seen from panel c) of Figure 10 . Since leverage $K / N$ and the borrowing rate $R_{b}$ are determined at the beginning of the period, an increase in $R_{k}$ unexpectedly increases the borrower's income. This pushes up the curve in the right graph. If this effect is relatively weak, then aggregate defaults still increase, 
although by less than in partial equilibrium (point $C^{\prime}$ ). If, instead, the elasticity of $R_{k}$ to $R$ is high enough in absolute value, the curve on the right graph shifts by enough that defaults ultimately decrease (point $C^{\prime \prime}$ ). Put it simply, in general equilibrium the increase in income exerts the opposite effect on defaults when compared to risk-taking incentives, and potentially prevents risk-taking behaviour from materializing into higher defaults ${ }^{15}$

\section{Conclusions}

This paper studied the effect of an exogenous monetary policy expansion on the delinquency rate of US business loans and consumer credit. The risk-taking channel of monetary policy, widely documented in the literature, suggests that delinquency rates could increase after a monetary expansion. While this literature mainly discussed an ex ante incentive by bank, it is less clear whether ex post and backward looking measures of defaults, which are closely monitored by central banks, would be capable of displaying such additional risk.

Buch et al. (2014b) find that an exogenous monetary expansion tends to decrease (rather than increase) nonperforming loans. They interpret this result as the effect of the decreased interest rate burden for firms that follows the monetary expansion. In this paper I provide further evidence for their result, and then use a standard model of a debt contract featuring equilibrium defaults to interpret the results. In particular, I show that the delinquency rate of US business loans and consumer credit decrease in response to a monetary expansion. I then argue

\footnotetext{
${ }^{15}$ In the model, whether the general equilibrium effect prevails or not depends on the exact general equilibrium framework used. Compare, for instance, Hafstead and Smith (2012) and Afanasyeva and Güntner (2014).
} 
that the "credit view" of monetary policy formalized in the model by Bernanke et al. (1999) provides intuition for a general equilibrium effect consistent with the empirical result. The intuition is that a monetary expansion increases income and profits, and hence improves the repayment possibility of borrowers. 


\section{References}

Afanasyeva, E. and J. Güntner (2014). Lending standards, credit booms and monetary policy. Technical report, IMFS Working Paper Series.

Altunbas, Y., L. Gambacorta, and D. Marques-Ibanez (2014). Does monetary policy affect bank risk-taking? International Journal of Central Banking.

Angeloni, I., E. Faia, and M. L. Duca (2015). Monetary policy and risk taking. Journal of Economic Dynamics and Control 52, 285-307.

Bańbura, M., D. Giannone, and L. Reichlin (2010). Large Bayesian vector auto regressions. Journal of Applied Econometrics 25(1), 71-92.

Barakchian, S. M. and C. Crowe (2013). Monetary policy matters: Evidence from new shocks data. Journal of Monetary Economics 60(8), 950-966.

Bernanke, B. S., M. Gertler, and S. Gilchrist (1999). The financial accelerator in a quantitative business cycle framework. Handbook of Macroeconomics 1, $1341-1393$.

Buch, C. M., S. Eickmeier, and E. Prieto (2014a). In search for yield? survey-based evidence on bank risk taking. Journal of Economic Dynamics and Control 43, $12-30$.

Buch, C. M., S. Eickmeier, and E. Prieto (2014b). Macroeconomic factors and microlevel bank behavior. Journal of Money, Credit and Banking 46(4), 715751. 
Cochrane, J. H. (2004). Comments on a new measure of monetary shocks: Derivation and implications by Christina Romer and David Romer. URL http://gsbwww. uchicago. edu/fac/john. cochrane/research/Papers/talk notes new measure 2.

Coibion, O., Y. Gorodnichenko, L. Kueng, and J. Silvia (2012). Innocent bystanders? monetary policy and inequality in the us. Technical report, National Bureau of Economic Research.

Covas, F. and W. J. Den Haan (2012). The role of debt and equity finance over the business cycle. The Economic Journal 122(565), 1262-1286.

De Graeve, F., T. Kick, and M. Koetter (2008). Monetary policy and financial (in) stability: An integrated micro-macro approach. Journal of Financial Stability 4 (3), 205-231.

Dell'Ariccia, G., L. Laeven, and G. Suarez (2013). Bank leverage and monetary policy's risk-taking channel. Technical report, International Monetary Fund.

Gertler, M. and P. Karadi (2015). Monetary policy surprises, credit costs and economic activity. American Economic Journal: Macroeconomics 7, 44-76.

Jimenez, G., S. Ongena, J.-L. Peydro, and J. Saurina (2014). Hazardous times for monetary policy: what do 23 million loans say about the impact of monetary policy on credit risk-taking. Econometrica 82(2).

Maddaloni, A. and J.-L. Peydro (2013). Monetary policy, macroprudential policy, and banking stability: Evidence from the euro area. International Journal of Central Banking. 
Mertens, K. and M. O. Ravn (2013). The dynamic effects of personal and corporate income tax changes in the united states. The American Economic Review 103(4), $1212-1247$.

Romer, C. D. and D. H. Romer (2004). A new measure of monetary shocks: Derivation and implications. American Economic Review 94(4).

Stock, J. H. and M. W. Watson (2012). Disentangling the channels of the 2007-2009 recession. Brookings Papers on Economic Activity.

Townsend, R. M. (1979). Optimal contracts and competitive markets with costly state verification. Journal of Economic theory 21(2), 265-293. 
Figure 1: Aggregate delinquency rates
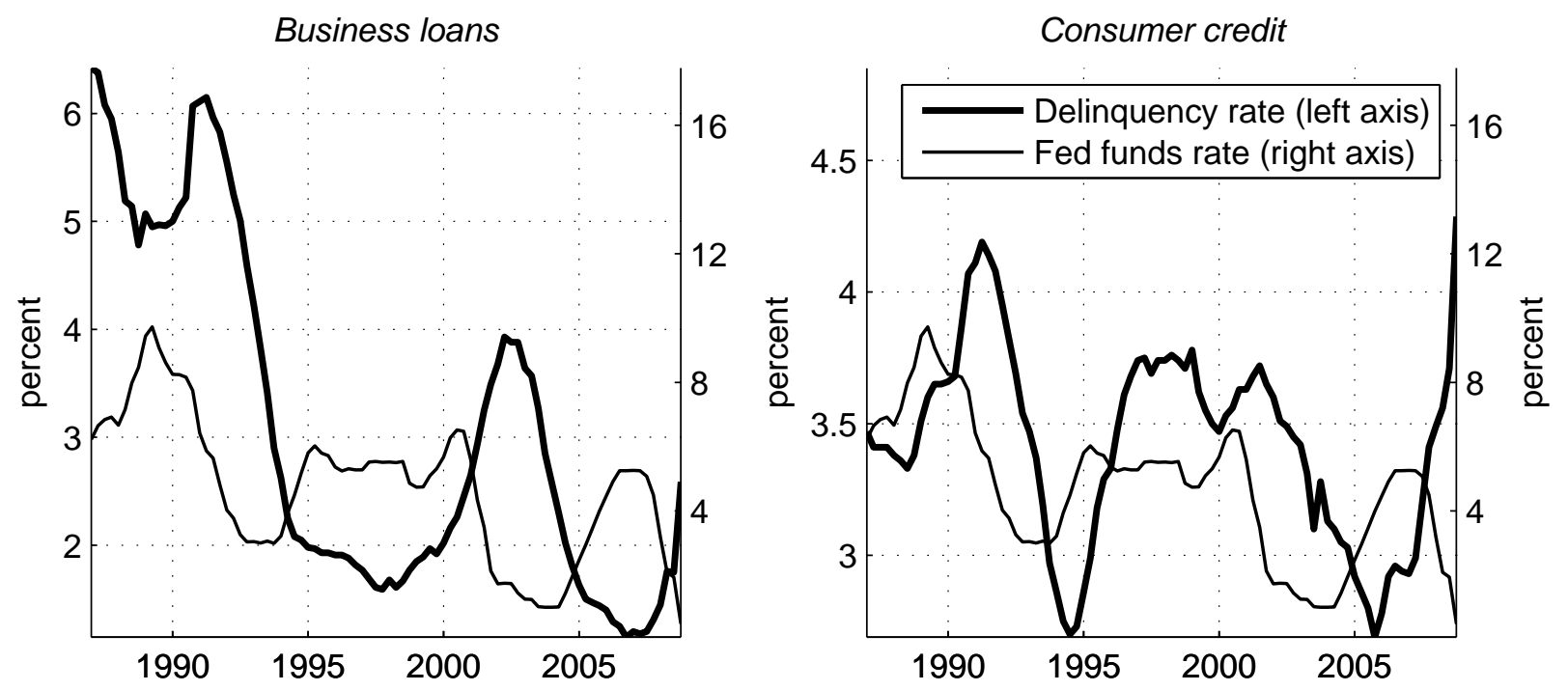

Notes: Deseasonalized delinquency rates and the federal funds rate in the period 1987Q12008Q4. 
Figure 2: Monetary shocks used in the identification of the SVAR

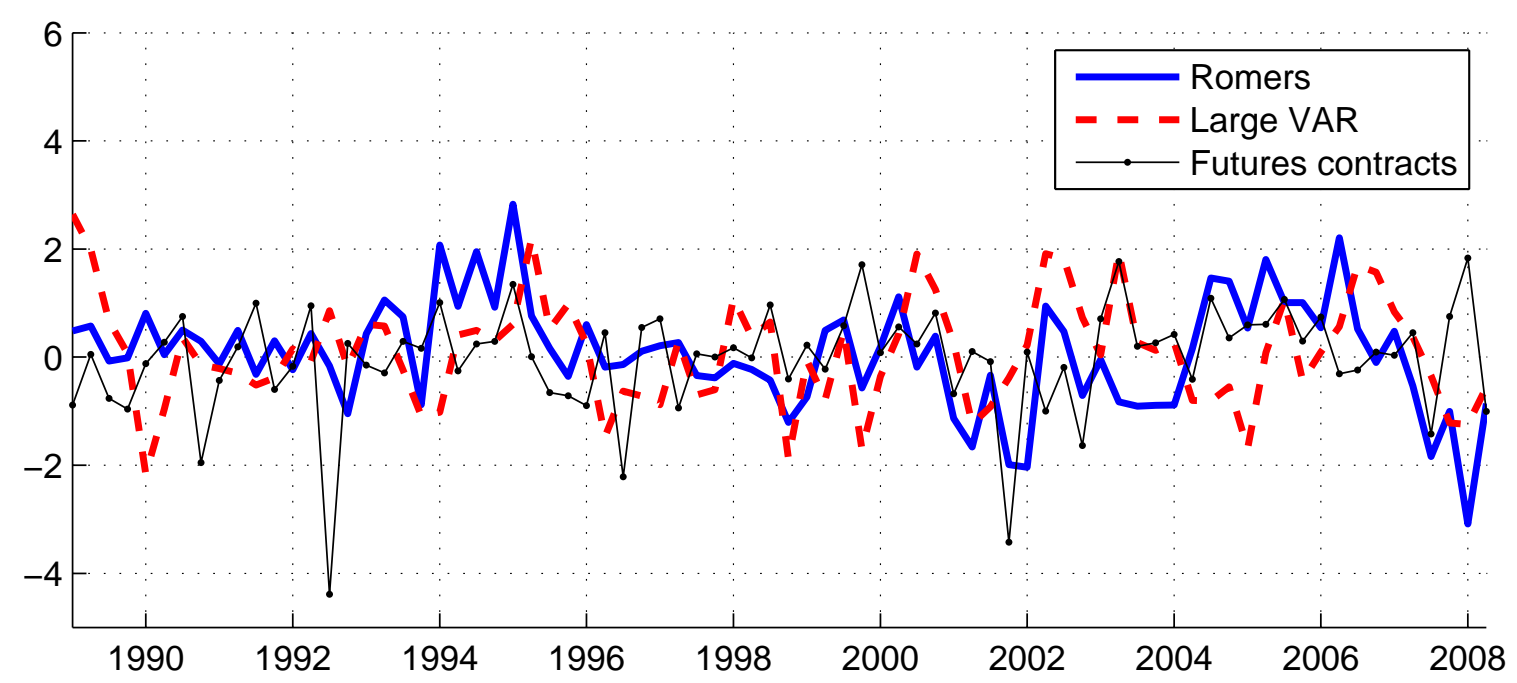

Notes: Shocks windsorized at 1\% and divided by standard deviation. The period reported is 1989Q1-2008Q2.

Table 1: Tests on the strength of the instruments

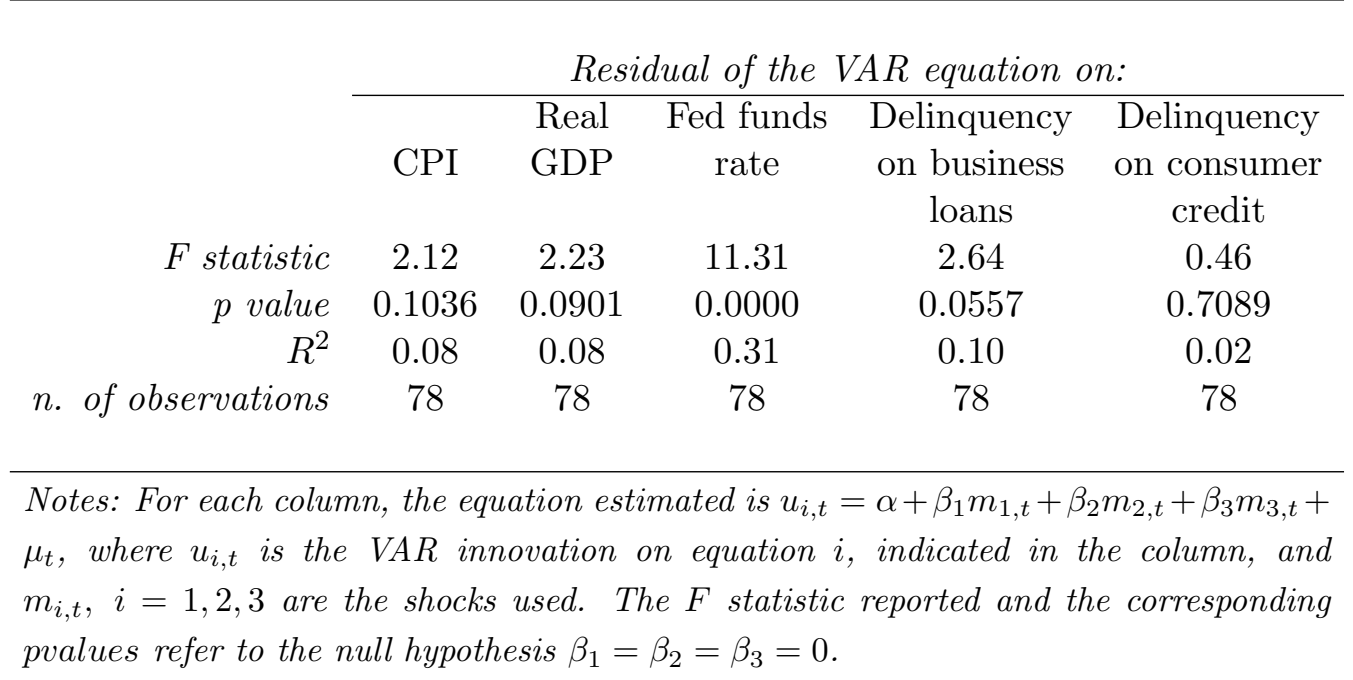


Figure 3: Impulse responses - expansionary monetary shock
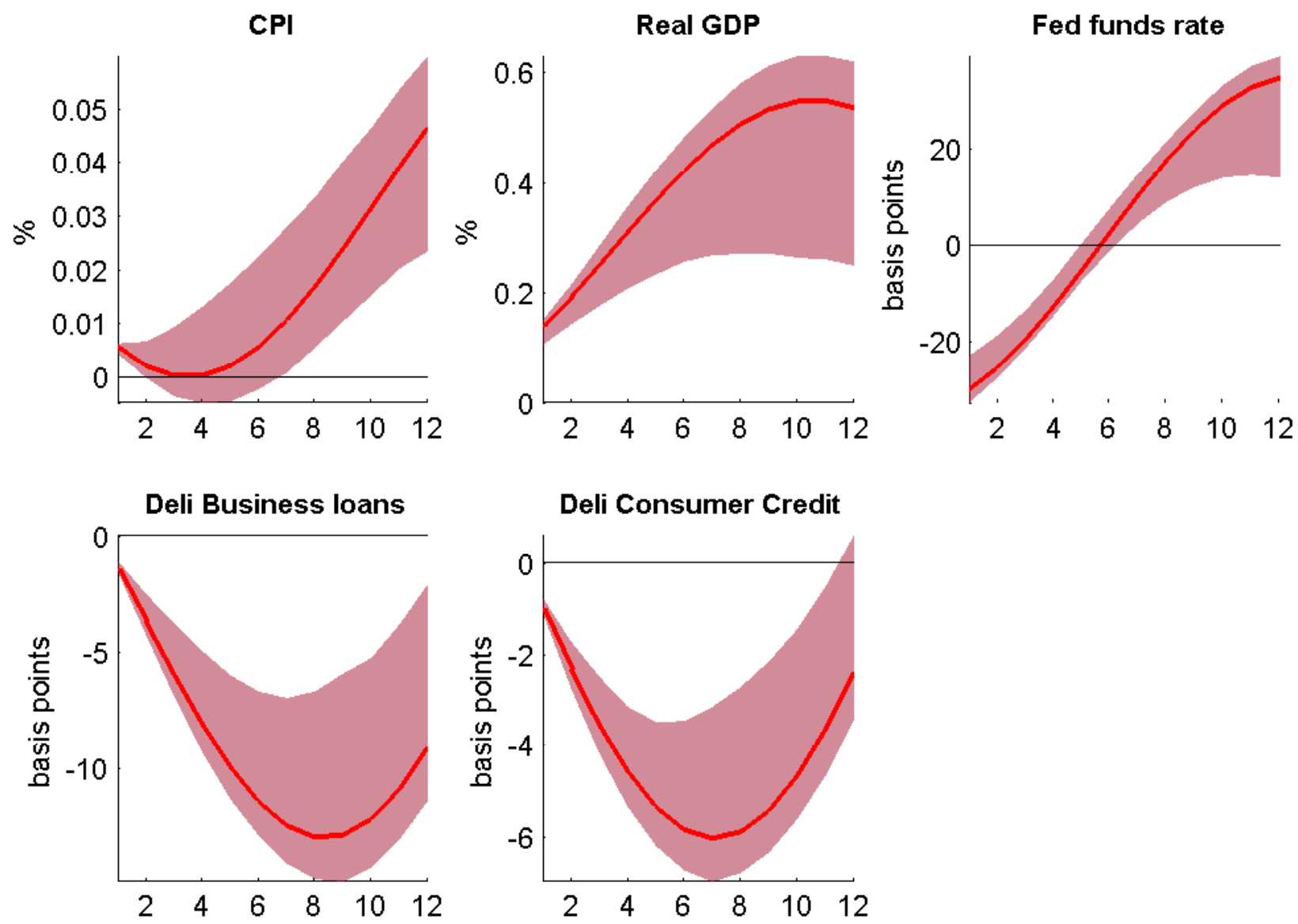

Notes: Expansionary monetary shock of one standard deviation. Pointwise 95 percent confidence bands reported based on 1000 bootstrap replications. 
Figure 4: Impulse responses - expansionary monetary shock using "orthogonalized" shocks
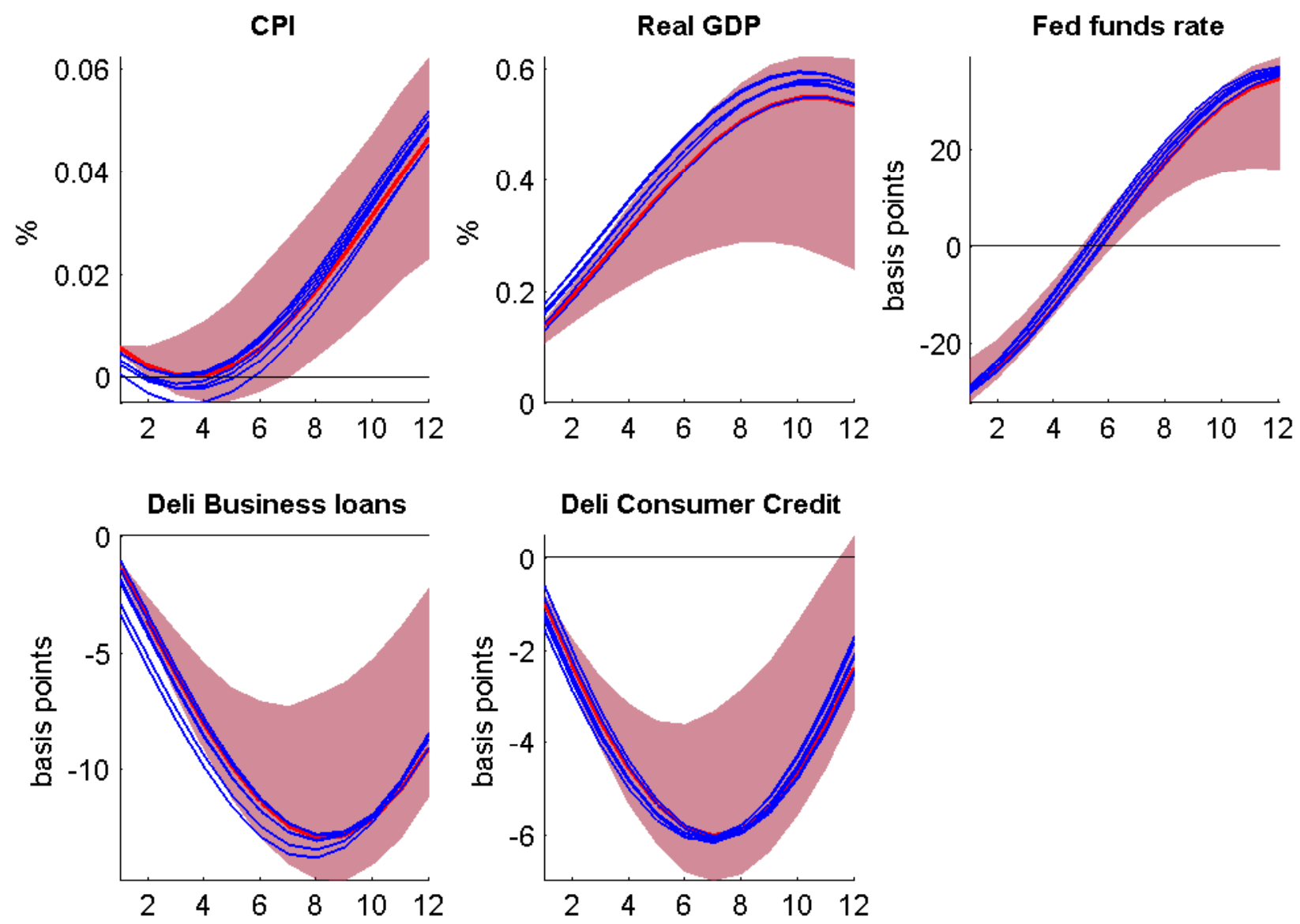

Notes: Expansionary monetary shock of one standard deviation. Pointwise 95 percent confidence bands reported based on 1000 bootstrap replications. 
Figure 5: Impulse responses - expansionary monetary shock using the three instruments one at the time
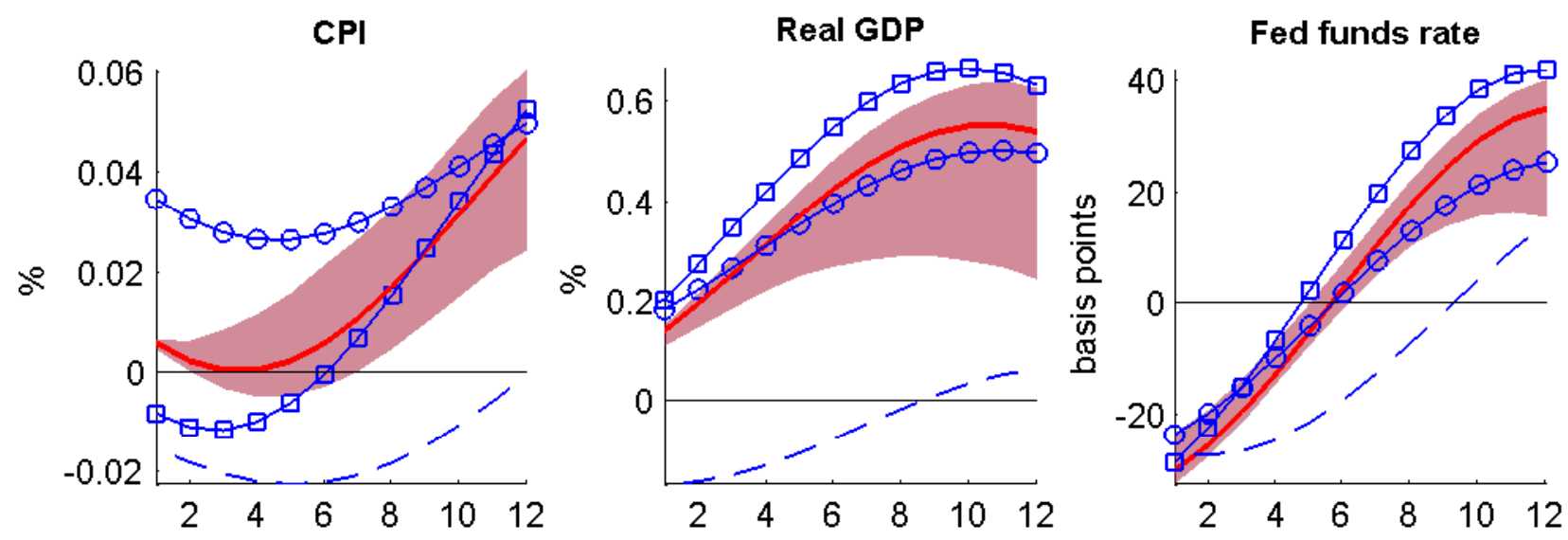

Deli Business loans

Deli Consumer Credit
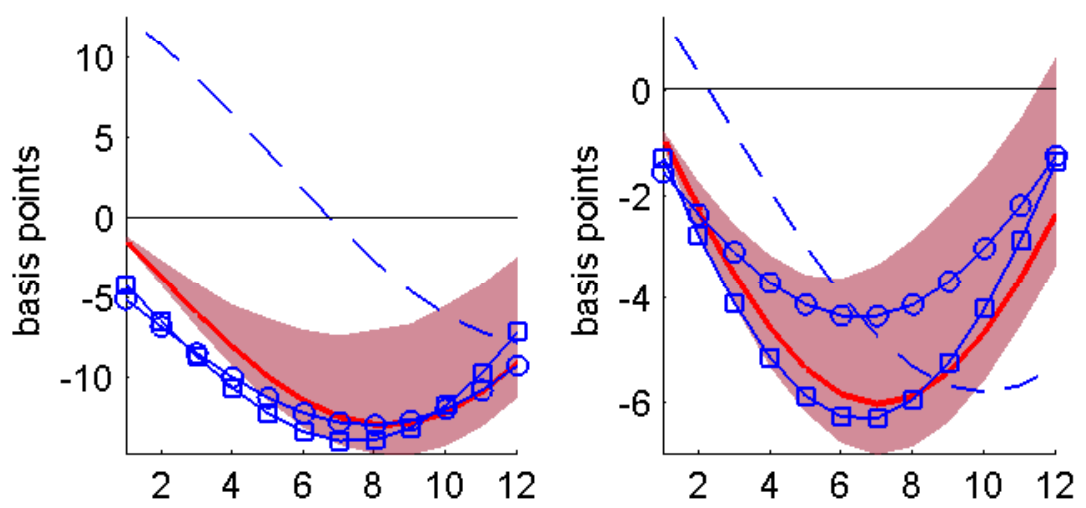

Notes: Expansionary monetary shock of one standard deviation. Pointwise 95 percent confidence bands reported based on 1000 bootstrap replications. Squared impulse responses correspond to the identification of the model using the Romer and Romer shocks. Circled impulse responses correspond to the identification of the model using the shocks from the large VAR model. Dashed impulse responses correspond to the identification of the model using the shocks from futures contracts. 
Figure 6: Impulse responses - alternative bootstrap methods
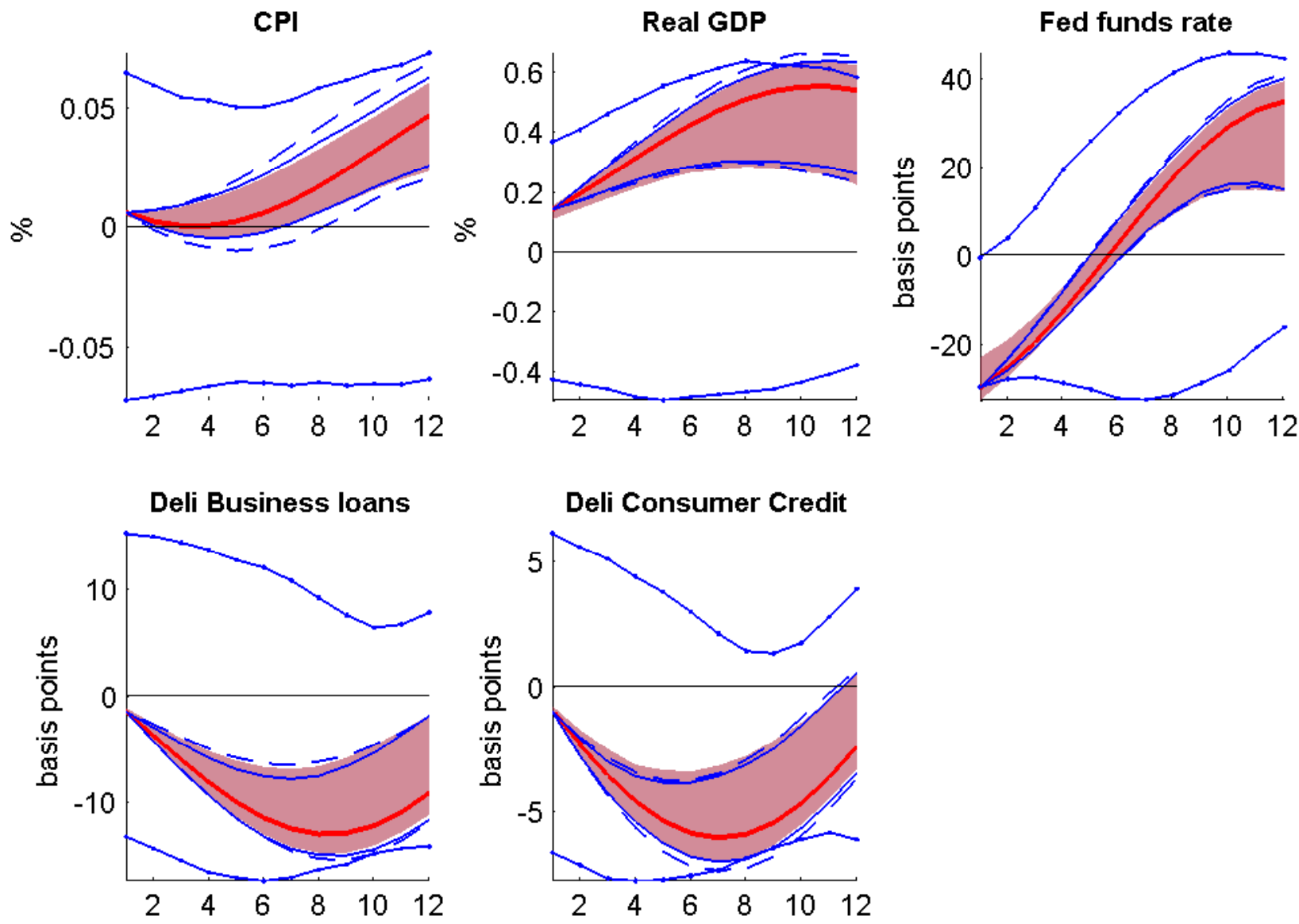

Notes: Shaded area and tick line refer to the baseline specification of the model and of the bootstrap. Solid, thin lines refer to the confidence intervals using the baseline bootstrap only on the autoregressive component of the model, not on the identification of the model estimated on each pseudo data. Solid, dashed lines refer to the confidence intervals using the wild bootstrap by Mertens and Ravn (2013) only on the autoregressive component of the model, not on its identification. Solid, dotted lines refer to the confidence intervals using the full wild bootstrap by Mertens and Ravn (2013), i.e. both on the autoregressive component of the model and on the identification of the model. 
Figure 7: Impulse responses - using only the Romer and Romer shocks
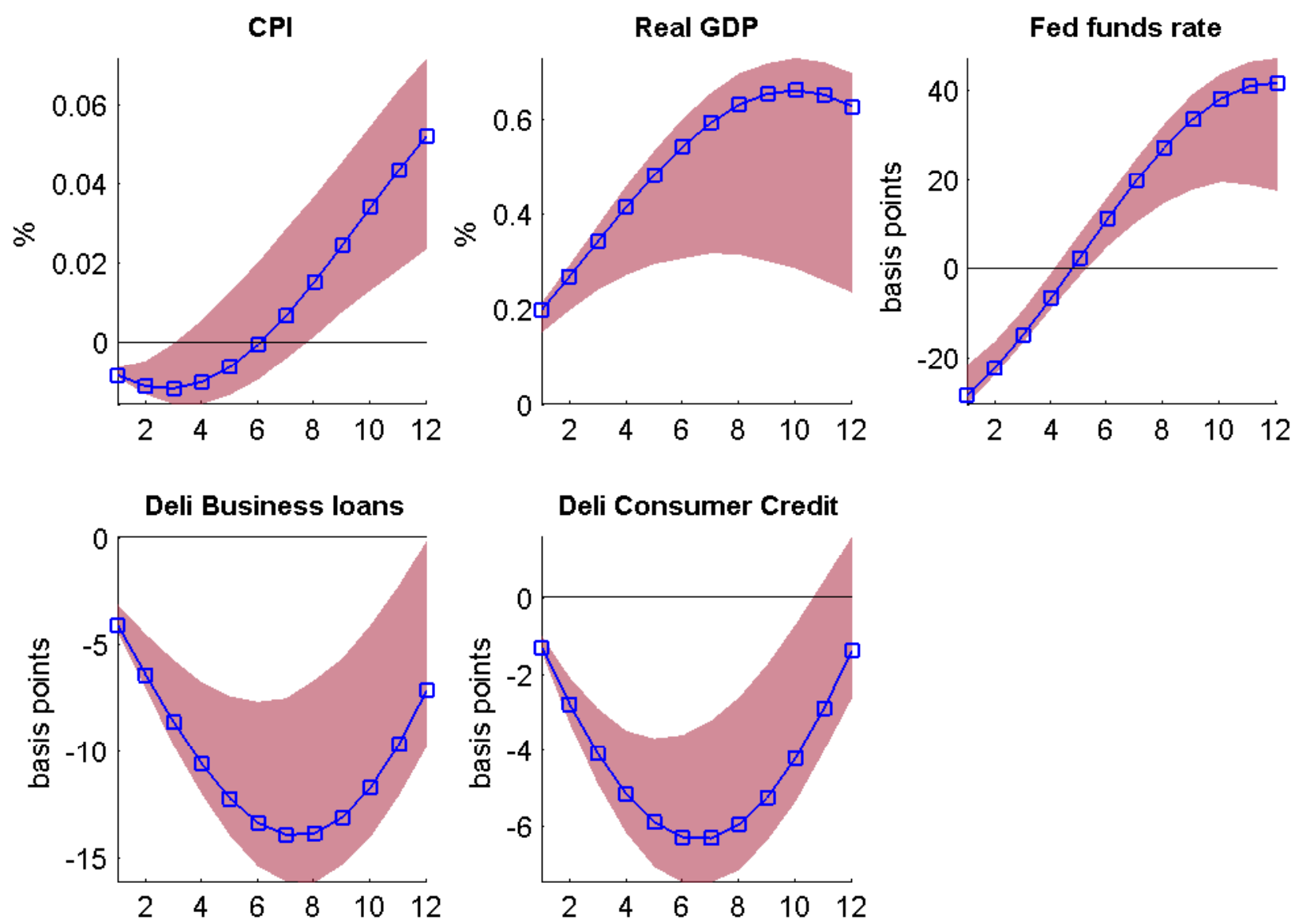

Notes: Expansionary monetary shock of one standard deviation. Pointwise 95 percent confidence bands reported based on 1000 bootstrap replications. 
Figure 8: Impulse responses - using only the shocks from the large VAR
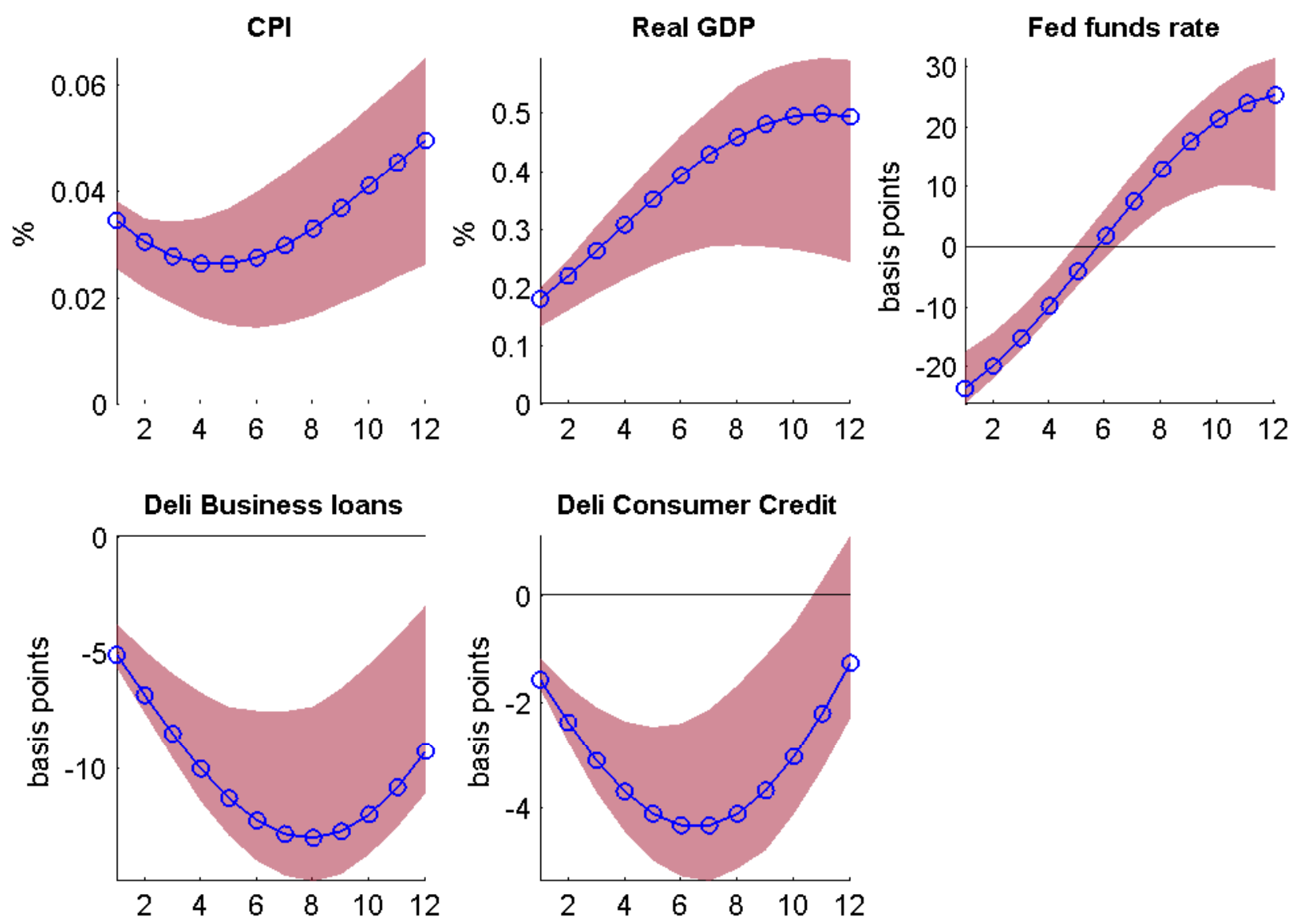

Notes: Expansionary monetary shock of one standard deviation. Pointwise 95 percent confidence bands reported based on 1000 bootstrap replications. 
Figure 9: Impulse responses - using only the shocks from the Futures Contracts on the federal funds rate
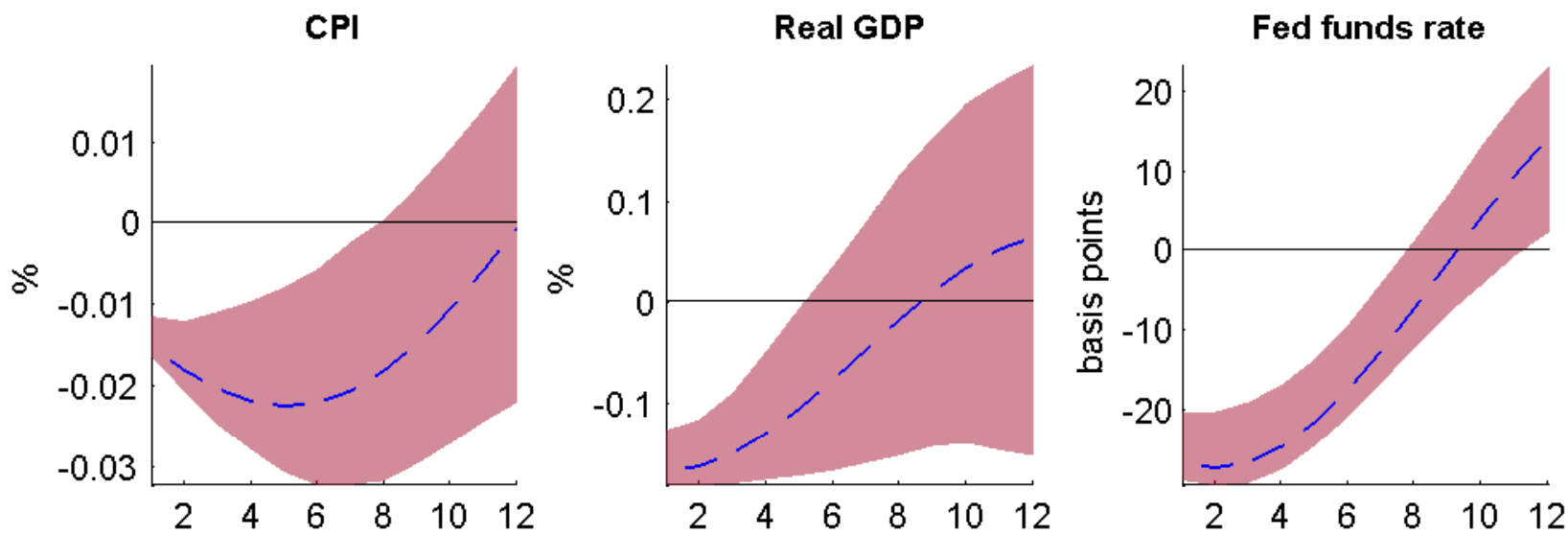

Deli Business loans

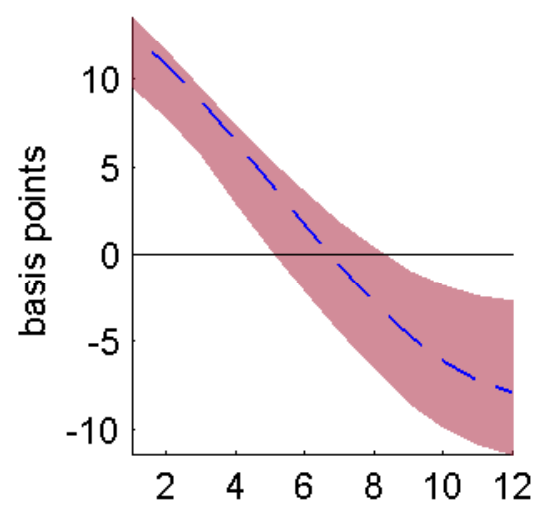

\section{Deli Consumer Credit}

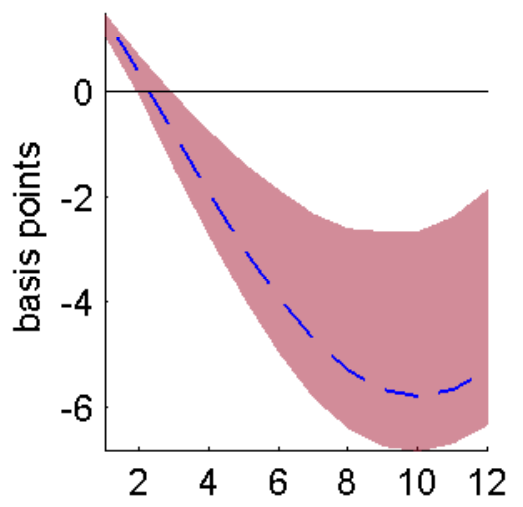

Notes: Expansionary monetary shock of one standard deviation. Pointwise 95 percent confidence bands reported based on 1000 bootstrap replications. 
Figure 10: Effects of defaults of a decrease in the opportunity cost of lending panel a) Initial equilibrium

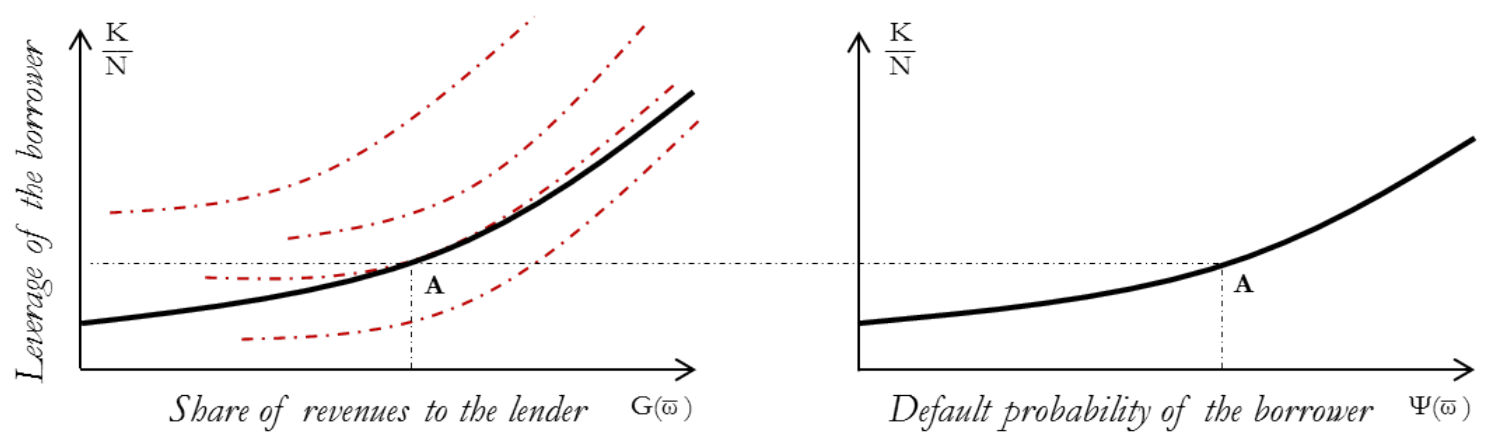

panel b) Partial equilibrium effect

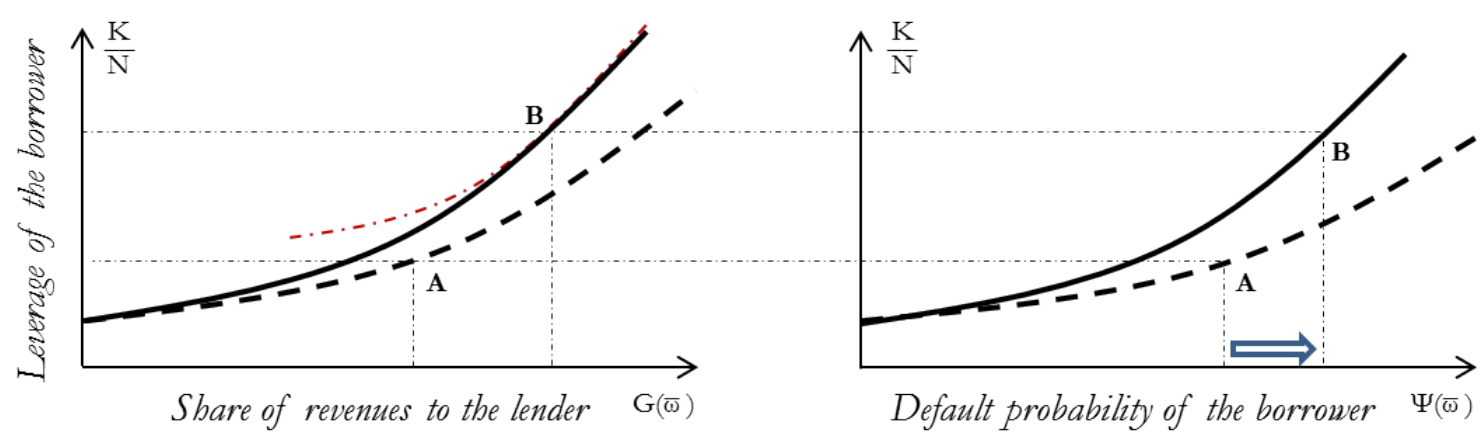

panel c) General equilibrium effect

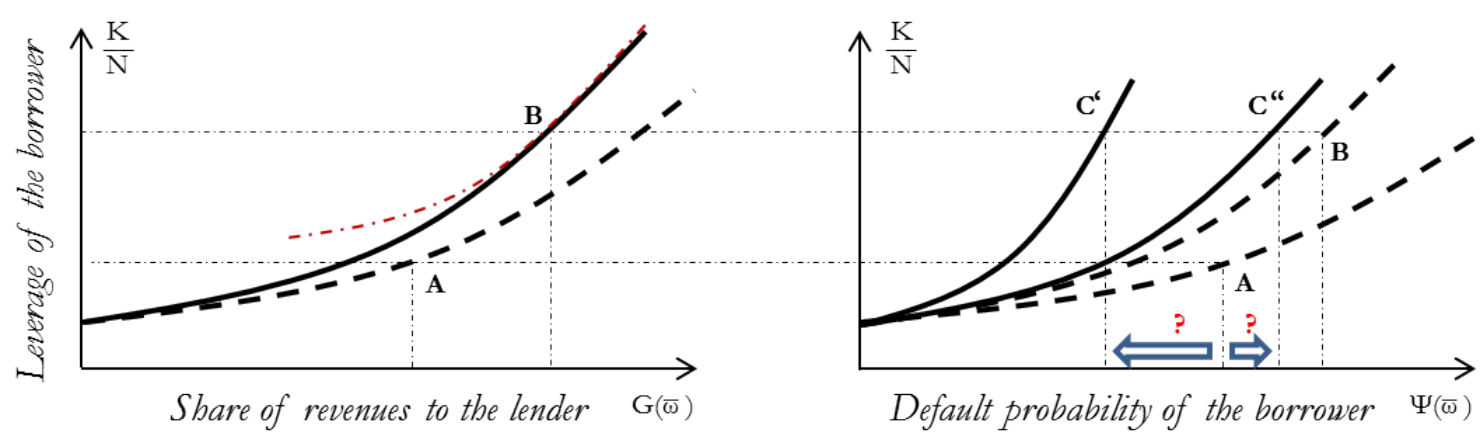

Notes: A decrease in the opportunity cost of lending relaxes the participation constraint of the lender and reduces the cost of borrowing. The borrower reacts to the lower cost of borrowing by leveraging up his net worth in order to invest more, and this increases the default probability (point B). In general equilibrium, the return to capital increases unexpectedly, exerting downward pressure on defaults (point $C^{\prime}$ and $C^{\prime \prime}$ ). If this effect is strong enough, equilibrium defaults decrease. 